\title{
The Issue of the Care of Orphans and Children made Vulnerable by HIV/AIDS (OVC) in Ivory Coast: case of the Dabakala region
}

\author{
TANO Kouassi Joseph ${ }^{1 *}$ SUN Qiu Yun ${ }^{2}$ \\ 1. Department of sociology, Huazhong University of Science and Technology, 1037 Luoyu \\ Road,Wuhan,Hubei,430074,China, \\ 2. Department of sociology, Huazhong University of Science and Technology, 1037 Luoyu \\ Road,Wuhan,Hubei,430074,China.
}

\begin{abstract}
The epidemic of HIV/AIDS continues to increase the number of Orphans and Children made Vulnerable due to HIV/AIDS (OCV). One of the most serious problems facing the governments, the International organizations and the Non-Governmental Organizations (NGO) in the organization of their response is the absence of data on quality of the services and the effectiveness of their interventions. An orphan is a child of less than 18 years who has lost one of his/her parents or both due to HIV/AIDS. In Ivory Coast, an Orphan of the HIV/AIDS is a completed Older child from 0 to 17 years which lost at least a relative because of the AIDS. It is also a child in situation of vulnerability due to HIV/aids is infected; whose at least relative lives with HIV/AIDS or which lives in an affected household economically by HIV/AIDS (where saw an infected adult.). The objective of this study aims a social-anthropological approach of the assumption of responsibility of the OCV. It aims making an inventory of all the public structures, nuns, NGO, or other speakers in the HIV and/or in favor of the children, likely to deal with of the OCV and identifying and at analyzing the offer of the services as regards assumption of responsibility and accompaniment of the OCV.
\end{abstract}

Keywords: Assumption of responsibility, Orphans, Children vulnerable, HIV/AIDS

DOI: $10.7176 /$ RHSS/9-2-15

\section{Introduction}

In Ivory Coast the HIV/AIDS crisis started since September 19th, 2002 heavily burdened the development programs, of started health. The living conditions of the populations were strongly degraded with the separate of the country into two, the recrudescence of unemployment, the destruction of the goods and public services and deprived, the abuses all kinds. Impoverishment, poverty, the food insecurity, the HIV/AIDS made only increase the precariousness of the life of the populations, particularly that of the children. The children already object of various exploitation paid a heavy tribute.

For more than 10 years, Ivory Coast is resolutely engaged in a total reduction policy of the HIV/AIDS pandemic. The 2010 crisis somewhat hindered the momentum and accentuated the deterioration of the living conditions of an estimated population of about 23 million. Ivory Coast, however, remains the most affected countries in the West African sub-region by HIV/AIDS.

The situation of the orphans and other children made vulnerable (OVC) on the site of Dabakala, is registered a social-anthropological approach of assumption of responsibility of the orphans and other children made vulnerable because of HIV/AIDS (NP-OVC). After several studies on the OVC, this research aims at analyzing the various orientations of assumption of responsibility of the OVC.

This creates more orphans and children vulnerable due HIV/AIDS. Their families are faced with serious health, social and economic problems, related to the trauma that causes this disease and the depletion of household income. This is why the NGO ACE since 2011 with HOPE Worldwide partner is committed to take care of OVC in Dabakala by providing care and support to over 600 OVC.

A child made vulnerable by the HIV/AIDS is a person of less than 18 years who lost one of his/her parents or both, or of which one of the parents is chronic illness (that this relative lives or not in the same household as the child), or who lives in a household where, during the last 12 months, at least, an adult is deceased after having been sick during three the 12 months having preceded his death, or which lives in a household where, at least, an adult was seriously sick for at least three months during the 12 passed months, or which are private of family protection (i.e. lives in an institution or the street).

Beside these children made orphan, million others see their health, their education, their safety where them morality compromised because of the disease or the death of a close relative or many members to their 
community. Examples: Children's in the street, the children victims of traffic, children affected by an armed conflict, driving or sensory handicapped children and the children victims of the worst forms of work.

Indeed, within the framework of this study, eleven (11) structures and organizations intervene in the field of the HIV/AIDS. One counts four (04) public structures, any private structure and seven (07) Non- Governmental Organizations and Religious organizations.

On the level of the education system, the cover of the zone in infrastructure and a teaching personnel is weak from where one of the difficulties to reach formal education. Also, if one relies on the median number of pupil per teacher (at least 38 pupils/teaching on the level of the primary education and 03 pupils/teaching on the level of the pre-school one and, at least 73 pupils teaching on the level of the secondary), one could retain that teaching would be of quality less. It is to be also noticed that the State is large offered of service with $69 \%$ of cover in infrastructures. The recent return of the DMOSS (November 2007) in the locality of Dabakala is an encouraging sign the more so as this structure seems the educational structure of reference in the assumption of responsibility and the accompaniment of the OVC.

At the medical level, the cover as some personnel of the department is weak. In the infrastructure (01 health centre for 9.915 inhabitants including 5.724 children who have an age ranging between 0 and 18 years) would be weak also if one relies on the national standard of the Sanitary institutions of First Contact (ESPC) which is of 13.156 inhabitants for a ESPC. The sanitary situation on the level of the medical District of Dabakala is less alarming because the structures of fight against the HIV/AIDS and assumption of responsibility of the OVC do not exist and many are those which were rehabilitated by a partner with the development in fact the UNICEF. The majority of the medical structures is functional but suffer from a deficit of qualified personnel.

The nonfunctional Social center because being occupied by the cabinet of the armed forces of the new forces. This social center must thus be rehabilitated because confronted with difficulties of a material, logistic and human nature. The social-educational complex is in a deplorable state and urgently requires to be rehabilitated. As service providers of the children, this structure exists only of name because victim of plundering and occupation to the favor of crisis of September 2002. This structure needs to be given in state within a reasonable delay and equipped with its manpower in order to relieve the vulnerable layers of the population.

On the level of the organizations, force is to note that an attempt at answer is given. To the level of the request, structures offer services of support however; these services are not made according to the standard of the national directives. As for the coordination of the activities of the actors of ground intervening in the field of HIV/AIDS brought an important contribution.

That is perceptible through the indicators with the social status, educational and medical.

The demographic data only raise that $49,30 \%$ of the OVC are of male sex against $50,70 \%$ of female sex, $42,3 \%$ would be provided education for, 53,70 would be not provided education for and $9,1 \%$ are not concerned with the educational statute. As regards the expressed needs, 79,50\% of the OVC indicated that the food support and the medical support $(62,80 \%)$ constitute for them the priority. The majority of the OVC is of female sex and their age bracket ranges between 6 and 13 years. Moreover, the majority of the OVC are under the supervision of the mother (30\%), follows the large parents $(13,4 \%)$.

The majority of the parents and substitutes questioned are of female sex $(55,6 \%)$, the number of commercial amounts to $70 \%$, the number of farmer/grower is of $10 \%$ and the number of without employment is of $(5 \%)$. Moreover, according to this target the OVC evoke needs for schooling (85\%); medical (100\%) and economic $(100 \%)$.

\section{I- Literature Review}

The HIV/AIDS has became such extensive epidemics in the space of a quarter century that generates the most pessimistic observations today. For proof, according to the last reports/ratios of UNO AIDS, more than 39,5 million people would live with the HIV/AIDS throughout the world and Africa Sub-Saharan with it only would count more than 24,7 million people of which are children. The situation is all the more alarming, that this plague is destroying the life of thousands of children. These last years, while the worldwide economy posted a rapid growth, the number of people living in poverty rose considerably. One counts for this purpose more than 1 , 2 billion inhabitants of which more than 600 million are children. They set up the most exposed group with the abuses and the violations of the basic rights of the man. 
Many International, National Organizations and the Government's actions in favor of the children welfare undertook, it appears that all did not profit from these actions and are always threatened by a poverty growing and exposed to the diseases. The economic situation and social is such as in certain countries, several million children live in the destitution, with the catches with the delinquency, the disease, malnutrition. Often without residence, without family framing, nor school, they represent indeed, the most vulnerable beings. They are increasingly numerous these children who lost their parents because of the HIV/AIDS or then which undergoes the effects of this disease by the presence in their immediate entourage people suffering from the HIV/AIDS. In Ivory Coast the crisis started since September 19th, 2002 heavily tested the development programs, of health started. The living conditions of the populations were strongly degraded with the separate of the country into two, the recrudescence of unemployment, the destruction of the goods and public services and deprived, the abuses all kinds.

Impoverishment, poverty, the food insecurity, the HIV/AIDS made only increase the precariousness of the life of the populations, particularly that of the children. The children already object of various exploitation paid a heavy tribute.

Concerning the HIV/AIDS, the children remain the first people affected by this irrefutable fact, and the emergency measure of the government were thus the installation into 2003 of a program with responsibility of bring an adequate answer to the problems of all these orphans and other vulnerable children because of HIV/AIDS (OVC): The National plan of Assumption of responsibility of the orphans and other Children Vulnerable because of HIV/AIDS (NP-OVC)

According to the NP-OVC, the Ivory Coast would count approximately 540.000 orphans and vulnerable children because of the HIV/AIDS; one of the answers brought to the crisis was to set up a national plan especially in charge of this question. To bring an adequate answer to the problems of the OVC, this program carries out an analysis of the situation in order to determine the strategic axes of its interventions. Thus, of 2004 to 2008, the NP-OEV carried out an analysis of the situation on 12 sites (Abobo, Yopougon, Abengourou, Bondoukou, Yamoussoukro, San-Pedro, Daloa, Dimbokro, Agboville, Bouaké, Korhogo and Man).

To date the capacities of the actors of the assumption of responsibility of the OVC were reinforced, their activities redynamized through platform of exchange and collaboration. It is to say that the services offered to the OVC improved with the result that these children go more or less better.

In implementation of its activities, 4 new sites among which we have Dabakala were identified by the NP-OVC. That with the aim of extend and to reinforce the actions in favor of the OVC to the national chess-board. Thus, various structures want to undertake studies of bases to appreciate the situation of the OVC and to bring the adequate answers to their needs.

The thorny question of the AIDS constitutes since second half of the 20th century, one of the problems which the sociology of health studies. Several theories have had try to explain the bonds of this pandemic with the social behaviors can be gathered in two principal paradigms (determinism and actionist) who's the particular paradigms like functionalism depend, of the culturalism, of the dialectical one, of the internationalism, individualism methodological, the paradigm and the rational choice.

Based on the postulate which "any element of any culture, corresponds a function and to any function corresponds an element", the step of functionalism is to identify the functions and the dysfunctions in the analyzed situations and to recommend the solutions suitable to exceed them (Omar Aktouf, 1987). From this point of view, studies aimed on "AIDS, let us speak" (ONUSIDA, 2001) watch that the muti-partnership and it not use of the condom support the expansion of the AIDS in the world.

In addition, in the context of functionalism, the approaches "biological kind" and " " inform us on sexuality. The kind indeed, returns to the range of the roles and reports/ratios determined by the company, with the features of personality, the attitudes, the behaviors, the values, the influence and the relative capacities that the company allots to the men and to the women according to their differences. By the functions of human reproduction and education, the man and the woman remain one and the other of the inevitable actors.

In addition, functionalism, by the biological approach conceives that the sexual activity results from a vertical function of the hormones starting from adolescence. The more the level of the hormones increases, the more the sexual activity becomes intense (Beach, 1974). Increased by Bancroft et al. (1986), the sexual activity is function of a natural hormonal mechanism, therefore biological. Rwenge (1995) attests that this one is the result of a biological impulse that the individual seeks to satisfy any price, directly or indirectly. 
The functionalist paradigm appears fundamental sometimes then because it describes behaviors due to a failure sometimes with a weakness of the institutional roles. Also, it describes the complexity of the matrimonial reports/ratios related to various perceptions relating to the use of the condom in the couples.

For the social organization in the Djimini company is founded on the centralization of the capacity. This capacity is held by the chief of the big family. Two types of system of relationship exist at Djimini. It is about the system of relationship of the matrilineal type and the system of the matrilineal type. Indeed, the system of the matrilineal type aims to attach the individual to his maternal family. Under these conditions, the father is discharged from the load of the child because it is ensured by the maternal uncle. Of this fact when a relative die, the problem of substitute did not arise more especially as it is the uncle who had the guard of the child.

Today, with the phenomenon of the religion and the school, the things changed. Indeed, with the absence of the one of the parents biological, it is the different one which ensures the guard of the child. However, some rare times it is assisted by other family members. The system of relationship of the matrilineal type which aims to attach the individual to his paternal family. In this case, the child inherits on the paternal side. To the absence thus of the father, the child is allocated to the alive relative who with the task to deal with this last as a parental substitute.

Moreover, the need for children for company names, economic and cultural is presented in the form of an obstacle to the use of the condom (Socpa, 2000). What would justify the sexual relationships without protection and thus a sexual behavior at the risk which can explain the infection with HIV at the individuals?

Obviously, none the use of the condom for the cultureless is related on the values, the beliefs, the habits, perceptions and traditions even with the manners of thinking, of feeling and of acting of the individuals relating to the social institutions which control them. Foucault (1984) affirms in that the sexual behaviors in the traditional society, far from being free, were determined by social-cultural standards and values.

\section{II- Methods}

\section{II-1 Study design}

The study was designed at the same time quantitative and qualitative. It is based on the dialectical step like mode of data analysis received from the populations. The target populations concerned are the rural populations whose age lies between 15 and 49 years. By the technique of quota and using the formula of SCHWARTZ the given sample rises with 2000 individuals envisaged to the departure but 596 retained finally account due to badly well-informed cards. For Children from 5 to 17 years. Thus, the tools for data acquisition used are the guide of maintenance and the questionnaire. The data collected were stripped manually initially, in order to establish the codes of the open-ended questions. In order to collect the qualitative and quantitative data, we had used the methods of data-gathering such as the documentary review, the individual and institutional talks using the guides of talks and the questionnaires. Then, the data were treated using software EPI-INFO VERSION 6. Lastly, the data were transferred towards software SPSS version 13.0. This last with the characteristic to have orders supporting the near total of the elementary statistical analyzes and the tables cross.

\section{II-2 Study setting}

In order to collect qualitative and quantitative information, the methods of following data-gathering were used: The documentary review consisted with the meticulous exploitation of the management reports, the communications, the scientific publications, the registers, the reports/ratios of the RGPH 2010. Repertories of the international organizations, the public institutions and, associations and other governmental organizations operating in the field of the HIV/AIDS such as the NP-OVC (Ministry for the family, the Woman and the Social Affairs); the Management of Reciprocity and Social Works in school (Minister of education Main road), the National institute of the Statistics (Ministry for the Plan and the Development); Demographic study of Health (Ministry for the Public health); Family Health International; Ivory Coast, etc.

Also, let us be us addressed to the decentralized structures of the localities quoted above for the complements of relative information to aspects socio-demographic, geographical, economic, medical, educational etc. One can quote differentiation regional managements and secondary roads from ministry (DREN, District Medical, CHR, Center of Protection of Early childhood), General advice and private and par public institutions, I used also directed discussion and direct observations/visits. 


\section{II-3 Research sites and section of participants}

According to the objectives registered in the terms of references, three targets constituted the field of study. On the level of the primary target which is the OVC, 2.000 children would be recorded as OVC. From this population, 596 children constituted our sample of study. The secondary target was only made up of households having to their load of the OVC. So, 20 households constituted the sample for the study. The structures, associations and all the other groupings which deal with or likely to deal with the children constituted the tertiary target. For this reason, 07 organizations, 05 public structures), the District of health, the town hall, and the prefecture constituted the last sample. The area of the valley of Bandama is between the $7^{\circ} 15$ and $9^{\circ} 20$ of northern latitude and between the $3^{\circ} 35$ and $5^{\circ} 25$ of western longitude. In this area of the valley of Bandama, the climate has one dry season from November to March and a season of rain from April at October and tends to supplant the system at four seasons. The rains are characterized by many irregularities and a generally weak and variable pluviometry of $1000 \mathrm{~mm}$ in the department of Bouaké and with $1200 \mathrm{~mm}$ in the departments of Katiola and Sakassou. Although savanna is dominant in the area of the valley of Bandama, one finds there some forests dry or dense and of the forests galleries which push along the rivers on the level of the departments of Béoumi, Katiola, Sakassou and Dabakala. These vegetable zones undergo in a worrying way the harmful effects of the bush fires and forestry development and agricultural not very rational. Moreover, the principal rivers which irrigate the area are the Komoe river in the East and the Bandama river in the West. The population of the area of the valley of Bandama was of 812739 inhabitants according to the RGPH of 2008. This population accounts for $7,5 \%$ of the total population of the country for a surface of $8,8 \%$ of the national territory. This indicates, the demographic weak density of the valley of Bandama which remains one of the principal centers of the migratory movements to the profit of great forest zones of the country. Moreover, 54,67\% of this population of young people are female a fringe much more vulnerable vis-a-vis the pandemia of the HIV/AIDS. With the advent of the socio-politic and military crisis which has occurred on September 19th, 2002, this area knew a massive depopulation of these inhabitants.

Moreover, the population of the area of the valley of Bandama was made up before the crisis of $45 \%$ of autochtones for $38,2 \%$ of aliens and inhabitants. Moreover, the population of the area of the valley of Bandama was made up before the crisis of $45 \%$ of autochtones for $38,2 \%$ from aliens and $16,8 \%$ from abroad. The social organization of these two great groups ethnolinguistic is determining for the matrimonial mode and the social status of the child and the woman in the area of the valley of Bandama. As for the population of the Dabakala city, it would be of 9915 inhabitants on the basis of general census of the population and the habitat carried out in 2008. The population of the department of Dabakala is estimated at 122.240 inhabitants, that is to say a degree of concentration of $13 \mathrm{hbts} / \mathrm{km}^{2}(\mathrm{RGPH}, 2010)$. It covers a surface of $9.671 \mathrm{~km}^{2}$ and is located at $494 \mathrm{Km}$ of Abidjan the department of Dabakala belongs to the area of savannas and is located between the parallels $8^{\circ} 26$ and $10^{\circ} 27$ of Northern latitude and $5^{\circ} 17$ and $6^{\circ} 19$ of Western longitude.

The department extends on $70 \mathrm{~km}$. According to the same source, a little more half $49 \%$ of its population is male against $51 \%$ women. Fertility rate is identical to that of the zone rural savanna which is 6,6 children per woman according to the social surveys and of health of 1994. As the chart indicates it below, the department is limited: In North by the department of Kong and the department of Ferkéssedougou; In the south by the department of Me Bahiakro; In the West by the department of Katiola; In the East by the department of Bondoukou and Tanda.

\section{III-Finding and Discussion}

\section{III-1 Offer of service of assumption of responsibility and OVC accompaniment}

The couple HIV/AIDS poverty seems today a threat for the populations and mainly the children who are the vulnerable fringe of this population. Many national organizations and international and the government undertook actions in favor of these children (OVC) in Ivory coast. To the level of Dabakala, an investigation into the services offered by the structures to these children gives the results below. 
Table 1: Distribution of the structures by type of assumption of responsibility effective

\begin{tabular}{|l|l|l|}
\hline Types of assumption of responsibility & Manpower/12 & Percentage (\%) \\
\hline IST/AIDS prevention & 9 & 75 \\
\hline Medical support & 3 & 25 \\
\hline Food support and nutritional Economic Support & 4 & 33,33 \\
\hline Extra teaching and Training Psychological support & 4 & 33,33 \\
\hline Legal support & 6 & 50 \\
\hline Extra teaching & 3 & 25 \\
\hline Spiritual support & 4 & 33,33 \\
\hline Types of assumption of responsibility & 7 & 58,33 \\
\hline IST/AIDS prevention & 3 & 25 \\
\hline
\end{tabular}

The results show that on the sample of 12 surveyed structures exerting in the field of HIV/AIDS, 6 structures would make the assumption of responsibility of the OEV is $50 \%$ of the structures. More specifically, $75 \%(9 / 12$ structures) would make the prevention IST/VIH, 33,33\% (4/12 structures) would make the support food and nutritional, $25 \%$ (3/12 structures) the medical support, 33,33\% (4/12 structures) the economic support, $50 \%$ (6/12 structures) extra teaching and training, 25\% (3/12 structures) and 33,33\% (4/12 structures) would make the legal support. The results also show that no structure makes a spiritual assumption of responsibility.

The various figures show that the structures of assumption of responsibility on the level of Dabakala seem to specialize by type of assumption of responsibility except the food assumption of responsibility which is made by the 11 structures which intervene in the field of OVC. The reasons which could explain this situation are the following ones:

- the presence of the World food program which support majority of the organizations of Dabakala which intervene in the assumption of responsibility of the vulnerable populations;

- the fact that the structures which would have affirmed to assume of responsibility of the OVC are not sufficiently equipped to provide information on their activities which they would have carried out;

- the fact that the spiritual assumption of responsibility is very complex more especially as each child seems to practice of office the religion of the parents;

- low capacity of the structures to carry out projects for the PVHIV and the families of OVC.

\section{III-2 Demographic characteristics of the OVC}

It would be interesting to know the proportion of the orphans and non-orphans in the whole of the populations which they cover.

On 596 OVC, 186 OVC are because of HIV/AIDS is $31,21 \%$. Indeed, there are 109 boys either $58,60 \%$ against 77 girls or $41,40 \%$. That is specified in the table hereafter. 
Figure 1. Distribution of the OVC according to their statute

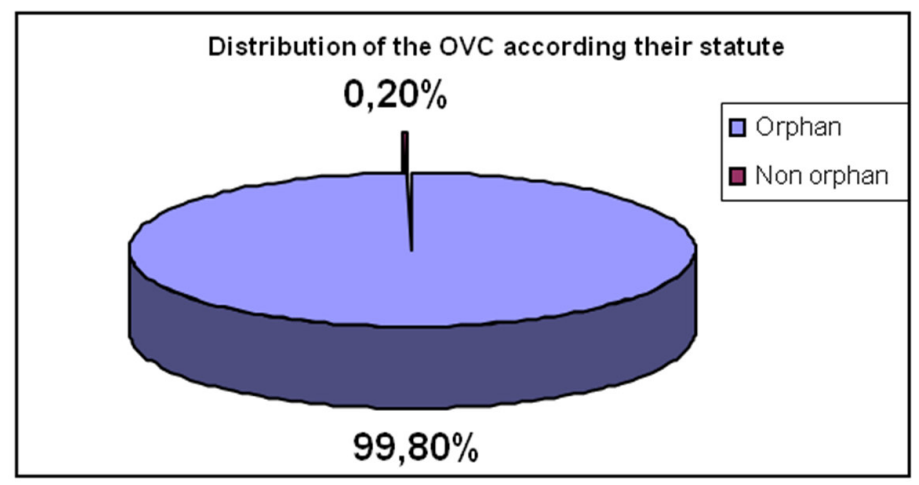

The analysis of the Figure 1 opposite shows us that the data that we received come primarily from the orphans. They account for $99,8 \%$ compared with $0,20 \%$ for non-orphans. Indeed, one notes 595 orphans against 01 only child not orphans. That is explained by the behaviors at the risk of these populations and the ignorance of the contraceptive methods as well as stigmatization related to HIV/AIDS. Because the majority of this population refuses to make her screening test of HIV/AIDS and thus she lives in total ignorance what supports even more the contamination of the disease. It also makes stress that the excision remains a subject taboo for the company Djimini and Djamala whereas this practice contribution to a high proportion. The only instrument is used for excised all the girls who must be subjected to this cultural initiation.

Table 2: Distribution of the orphans according to the sex and their statute

\begin{tabular}{|c|c|c|c|c|c|}
\hline & & \multicolumn{2}{|c|}{ sex of the child } & \multicolumn{2}{|l|}{ Total } \\
\hline Statute of the orphan & & Male & Female & & \\
\hline \multirow[t]{2}{*}{ father } & Manpower & 161 & 144 & \multicolumn{2}{|l|}{305} \\
\hline & site of the investigation (\%) & $52,79 \%$ & $47,21 \%$ & $100 \%$ & $51,26 \%$ \\
\hline \multirow[t]{2}{*}{ mother } & Manpower & 76 & 96 & \multicolumn{2}{|l|}{172} \\
\hline & site of the investigation (\%) & $44,19 \%$ & $55,81 \%$ & $100 \%$ & $28,91 \%$ \\
\hline \multirow[t]{2}{*}{ father and mother } & Manpower & 56 & 62 & \multicolumn{2}{|l|}{118} \\
\hline & site of the investigation $(\%)$ & $47,46 \%$ & $52,54 \%$ & $100 \%$ & $19,83 \%$ \\
\hline \multicolumn{2}{|l|}{ Total } & $293(49,24 \%)$ & $302(50,76 \%)$ & \multicolumn{2}{|c|}{$595(100 \%)$} \\
\hline
\end{tabular}

As this table indicates it, so much on the level of the girls than of the boys, the orphans of father are most numerous $(51,26 \%)$. It should be noticed that in all the types of statutes of the orphans, the girls are numerous that the boys. What is really of their educational statute? 
Table 3: Distribution of the OVC leaves sex according the educational statute

\begin{tabular}{|c|c|c|c|c|}
\hline \multirow{2}{*}{$\begin{array}{l}\text { Educational } \\
\text { statute }\end{array}$} & & \multicolumn{2}{|c|}{ Sex of the child } & \multirow[t]{2}{*}{ Total } \\
\hline & & Male & Female & \\
\hline \multirow[b]{2}{*}{ Provided education } & Manpower & 117 & 135 & 252 \\
\hline & site of the investigation (\%) & $46,43 \%$ & $53,57 \%$ & $100 \%$ \\
\hline \multirow[b]{2}{*}{ Education die } & Manpower & 9 & 15 & 24 \\
\hline & site of the investigation (\%) & $37,5 \%$ & $62,50 \%$ & $100 \%$ \\
\hline \multirow[b]{2}{*}{ Non-education } & Manpower & 168 & 152 & 320 \\
\hline & site of the investigation (\%) & $52,50 \%$ & $47,50 \%$ & $100 \%$ \\
\hline \multicolumn{2}{|l|}{ Total } & $294(49,33 \%)$ & $302(50,67 \%)$ & $596(100 \%)$ \\
\hline
\end{tabular}

This table shows us that among provided education for, girls OVC are most numerous with 50,67\% compared with 49,33\% among boys. Except this educational statute, 47,50\% girls do not go to school against 52,50\%. While $62,50 \%$ of the girls do not go any more to school against $37,50 \%$ of the boys. This data obeys so much is little with the cultural practices which always persist, and which make that as regards schooling, there is always a preference for the boys. That is still marked at the OVC.

Which is then their school statute by age bracket?

Figure 2. Distribution of the OVC according the educational level

\section{Distribution of the OCV according the educational level}
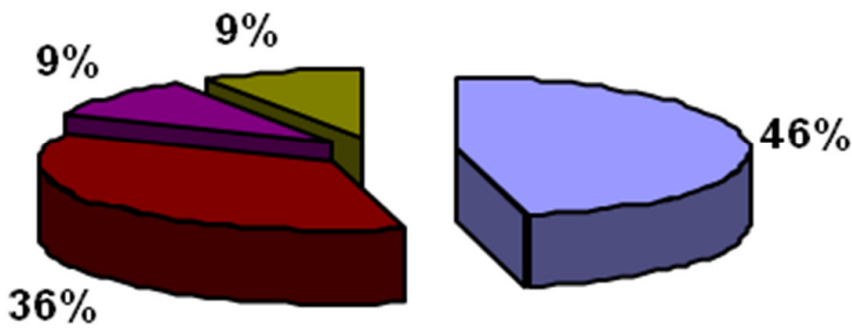

No level

Primary education

Secondary

Not concerns

The whole of the OVC identified during our investigation does not have any level 271 out of 596, either $46 \%$ of the OVC, 216 OVC or $36 \%$ have the primary education level. 55OVC are $9 \%$ represent those which are with the secondary and $55 \mathrm{OVC}$ are $9 \%$ are not concerned because these children do not have yet the age to go to school. The level of schooling is low in this locality. That is due to sociocultural gravitate related on schooling and the difficult conditions under which the families touched by the crisis live that our country crosses. This irrefutable fact finds its explanation in the graph hereafter. 


\section{III-3 Socio-demographic characteristics of the parents/substitutes.}

The sex, the educational level of the household, the religion and the educational level are elements which make it possible to appreciate the household. In this objective a study in the households was made. Examination of the results of the questionnaire managed watch which the Middle Age of surveyed is 41 years with respectively a minimum and maximum a 25 years and 60 years. The table below takes the action pursuant of the results of the examination.

\section{III-4 Households according to the sex, the profession, the religion and the educational level}

With the results of the investigation, one notes, $15 \%$ (3/20 families) heads of household is without employment, $70 \%$ (14/20 families) made a small shop and 10\% (2/20 families) are farmers or grower. As, it arises as 55\% (11/20 households) of the heads of household of this population do not have any level (illiterate), 35\% (7/20 households) has a primary education level and 10\% (2/20 households) a secondary level.

As for the question of religion, 75\% (15/20 households) of the households would practice the Islamic religion, $25 \%$ (5/20 households) the Christian religion.

It comes out from these data that:

- $90 \%$ of our sample are female sex against $10 \%$ of the male sex;

- the sex of the head of household is the female sex (65\% (single person, widowed, separate) against $35 \%$ of married).

Of all these indicators, one could retain that:

- there is no attribution of income to the housework, because the trade which they do does not produce of sufficient incomes to deal with the children;

- there is no personal valorization of these households;

- the surveyed families live under difficult conditions. It is to say that good number families of OVC lives under the conditions in the commune of Dabakala.

Consequently, the wellbeing of the children who are with their load is threatened because it could be that they are private good number of their rights. So, it would be interesting to support the heads of household and especially the mothers with AGR in order to enable them to improve quality of life of the children to their load. How is the framework presented life of the surveyed households?

\section{III-5 Expression of the needs for the parents and substitutes parental for the orphans}

The table below, indicates by priority that the food assumption of responsibility is the need which was expressed more by the parents and substitutes which have in load the orphans and that corroborates a little with the data analysis socio-demographic. Thus, after the needs for food assumption of responsibility (90,96\%), the needs for economic assumption of responsibility $(86,85 \%)$ and psychosocial $(86,85 \%)$ are expressed. The other catch of load like the medical assumption of responsibility $(83,48 \%)$ and school $(62,25 \%)$ are requested fairly compared to the legal assumption of responsibility $(40,91 \%)$ which was not certainly requested too much because the relative do not know of them too the values related to these assumptions of responsibility.

These needs do not represent for certain parents of the immediate needs or fundamental.

The parents and parental substitutes of the orphans of father are those which requested more the needs and that in type of needs. The report is that the mothers represent the majority of the people who have in load the orphans of father and in the majority of the cases, these women are stripped. To $86,85 \%$, they requested the economic assumption of responsibility (support for generating activities of returned) to come to assistance of their children.

In addition to this type of parents (orphan of father), one notices that the parents or parental substitutes of the orphans of full statute expressed more needs than the parents and parental substitutes for the orphans of mother in the fields for assumption of responsibility in terms of school stationery, school fees, medical monitoring and in appropriate dresses. 


\section{Conclusion and Recommendations}

The organizations which have activities of assumption of responsibility and/or of accompaniment of the orphans and other children made vulnerable because of HIV/AIDS (OVC) do an important work on the ground in spite of their thin means. They undertake activities in all the compartments which contribute as far as they can it with the improvement of the conditions of the Child problems.

The situation of the children living under difficult conditions does not make sufficiently known. And that on all the levels of interventions (social, educational and medical). But that is much more perceptible in the medical field. However, they are more and more confronted with cases of ill children or are affected by HIV/AIDS in front of which they remain without weapons because not having received a specific training on the matter.

The HIV became extensive in the department of Dabakala because of crisis military-policy. Within the framework of the fight against this pandemic, apart from the medical structures only the DMOSS which is a structure of the education system is the only public structure which seems to undertake activities of fight against the HIV. As for the private structures, no activity is undertaken for the period of our study. So, the disease is spirit to decimate the population in silence. It seems to be been unaware of by part of the population and in certain cases, it is a venereal disease because of discrimination and the stigmatization from which suffer the PVHIV and their families and particularly their children. This fact added to the culture of the zone, few actions is carried out in favor of the OVC and specifically those of the HIV.

Speaking about the problems of the OVC, it is of good tone to mean that they are the Governmental organizations who are suitable. They undertake activities of assumption of responsibility and accompaniment of the OVC even if they do not manage to satisfy the request of the OVC for various reasons. Consequently, force would be to adopt an approach implying the other actors. With this intention to achieve goals, measurements must be taken.

We also estimate that for the best implemented of the policy of national plan for the assumption of responsibility of the orphans and other children made vulnerable because of HIV/AIDS (NP-OVC) to Dabakala, it would be necessary:

- To rehabilitate and provide the social-educational complex as some personnel; to decentralize the National plan of Assumption of responsibility of the people living with HIV/AIDS and the Program of the Prevention of the Transmission Mother Child of HIV/AIDS (PTMC) at the peripheral level;

- To cause a synergy of actions through the installation of a platform of

collaboration between all the speakers in the PEC of the OVC; to make the promotion of the policy of the NPOVC on all the levels at the place of the structures intervening in the HIV/AIDS; to inform and train the actors of assumption of responsibility of the OVC on the problems of the OVC;

- To reinforce the capacities of the actors as regards assumption of responsibility of the OEV (dealt with psychosocial, school, etc.); to encourage the implication of the leaders (religious, of opinions,...) and administrative authorities and policies in the identification and the assumption of responsibility of the OVC; to rehabilitate and reinforce the capacity of the social-educative complex as a personnel and material; to integrate the problems of the OEV in the activities of the cell of fight against the HIV/AIDS of the ANADER; to continue the support in school stationery; to train the medical personnel with the regulation of the pediatric ARV; to make available the pediatric ARV; to multiply the policy of a school - a canteen;

- A training of the actors of ground in the psycho-social assumption of responsibility, the follow-up in residence and the medical monitoring of the OVC;

The average materials are placed at the disposal of the persons in charge in the execution of their task.

\section{References}

1. Ainswoerth, M., Fransen, L. andAl(1997). Confronting AIDS: Obviousness from the United Kingdom and AIDS analysis Africa. HIV/AIDS country profiles (Ivory Coast), p12- 40.

2. Aka, K.R., Soucat, A., Maville, E. (1995). current Costs and theoretical costs of the assumption of responsibility of the AIDS: need for rationalization of the activities of health professional trainings of Ivory Coast: CHU of Treichville, PNLS. Xème CISMA Abidjan 
3. Atelier of restitution of the Good practices and organization of fight against the HIV/AIDS, in the work world. Bassam, of the 11 April 13rd, 2005, final report

4. Beaud Michel. (2006). The Art of the thesis (Paris, ED. the Discovery, 202P).

5. Bou-Assy, F. (2001). Social representations of the endogamy and its biological effects on the health of the descendants at promised in marriage endogames: case of two Shiite villages in the west of Baalbeck. Laval university.

6. Communication for the behavioral change in the field of the HIV/AIDS in Ivory Coast: Analyzes strategies and response of 1985 to 2004, final report; Ministry for the Fight against the HIV/AIDS.

7. Kérouédan D, Weinger Mr. (Octoberm, 2004) Fight against AIDS in the work world in Ivory Coast. Elements of analysis of the situation and the answer. Family Health International.

8. Manuel of technical procedures for the PTME of the HIV in Ivory Coast (CI); Edition 2003, MSP3.

9. Ministry of the Fight against the HIV/AIDS. National fight plan against the HIV/AIDS 2006-2010 in Ivory Coast; Abidjan 2006

10. Ministry of Solidarity, the Social security and Handicapped the Document of National policy for the Assumption of responsibility of the Orphans and other Vulnerable Children because of the HIV/AIDS, Ivory Coast, November 2005

11. N'DA, Paul. (2012). Methodology of research: Problems with the discussion of the results, Abidjan, 2nd ED. EDUCI.

12. Partnership Public Private Civil society, a good practice for the fight against the HIV/AIDS in Ivory Coast, Ministry for the Public office and Employment, Family Health International, 2006.

13. Politic Main road of Total Assumption of responsibility of the People Living With the HIV, MEMSP, June 2005

14. Politic main road of PTME in Ivory Coast; (2006), MSHP.

15. Rapport annual over activities 2005 of HIV/AIDS in Ivory Coast, the Ministry in load of health, September 2006

16. Rapport of activities of fight against the HIV/AIDS of the Ministry for the family and the Social Affairs

17. Rapport of the analysis of the situation of the Orphans and other Children made Vulnerable due of HIV/AIDS in the commune of Bondoukou, NP-OVC/FHI/MSSSH, 2004.

18. Rapport of the analysis of the situation of the Orphans and other Children made Vulnerable due of HIV/AIDS in the commune of Dimbokro, NP-OVC DMOSS/FHI, 200,7 